\title{
Glycyrrhizin induces apoptosis in prostate cancer cell lines DU-145 and LNCaP
}

\author{
SIVASAKTHIVEL THIRUGNANAM, LIPENG XU, \\ KALYANASUNDARAM RAMASWAMY and MUNIRATHINAM GNANASEKAR
}

\author{
Department of Biomedical Sciences, University of Illinois, College of Medicine, Rockford, IL 61107, USA
}

Received May 20, 2008; Accepted July 2, 2008

DOI: $10.3892 /$ or_00000157

\begin{abstract}
Over 2 million Americans are currently living with prostate cancer. Current chemotherapeutic strategies are only partially effective in controlling the disease. There is always a need for an effective newer drug for treating prostate cancer. Use of active principles from medically important herbs has proven to be effective in treating various forms of cancers. Glycyrrhizin, a triterpene compound isolated from roots of licorice has been found to exhibit potent in vitro cytotoxic activity against several human cancer cell lines. In this study, we evaluated the effects of glycyrrhizin on the viability of two human prostate cancer cells LNCaP (hormone-dependent) and DU-145 (hormone-independent) in vitro. Cell viability assay showed that glycyrrhizin inhibited the cell proliferation of prostate cancer cells in a time- and dose-dependent manner. The decreased viability of prostate cancer cells was due to apoptosis as confirmed by Annexin-V FITC flow cytometric analyses. Glycyrrhizin also caused DNA damage in DU-145 and LNCaP cells in a time-dependent manner. Caspase- 3 and -8 activities were not detected in glycyrrhizin-treated prostate cancer cells suggesting that caspase-independent pathways may be involved in the apoptotic mechanism. Collectively, these studies suggest that glycyrrhizin has therapeutic potential against prostate cancer.
\end{abstract}

\section{Introduction}

Prostate cancer is the most common non-cutaneous cancer, with approximately 218,890 expected new cases and 27,050 deaths in the year 2007 in American men (1). It is the second most common cancer in men after lung cancer and prostate cancer incidence continue to increase every year. Although causes of prostate cancer remain obscure, there are several

Correspondence to: Dr Munirathinam Gnanasekar, Department of Biomedical Sciences, University of Illinois, College of Medicine, 1601 Parkview Ave, Rockford, IL 61107, USA

E-mail: mgnanas@uic.edu

Key words: glycyrrhizin, prostate cancer, LNCaP, DU145, apoptosis risk factors such as race, increasing age, and a family history that are significant risk factors for the development of prostate cancer (2). In the initial stages, prostate cancer can be treated by androgen-ablative therapy, surgery, radiotherapy or radical prostatectomy (3). Patients who respond to these therapies eventually fail to respond as the disease progresses and succumb to the disease because of the development of androgen-independent prostate cancer that progress into metastasis. Chemotherapy is the primary treatment for most types of metastatic cancer. However, conventional chemotherapeutic agents are often inadequate due to enhanced malignancy and multidrug-resistance by cancer cells. Therefore, development of effective chemotherapeutic agents is needed to control the metastatic stages of prostate cancer, which would enormously improve life expectancy of the patient.

Many dietary supplements and plant-derived products are shown to be promising anti-tumor therapeutic agents and are now being assessed in pre-clinical and clinical studies $(4,5)$. These anti-tumor agents usually activate the apoptosis pathways in tumor cells. Glycyrrhizin, a triterpenoid saponin isolated from licorice root, induce apoptosis in many cell types including human hepatoma (HLE), promyelotic leukemia (HL-60) and stomach cancer (KATO III) and Kaposi sarcomaassociated herpesvirus-infected cells $(6,7)$. Glycyrrhizininduced apoptosis causes DNA fragmentation and oxidative stress in cancer cells $(6,7)$. In addition to the anti-tumor effect, glycyrrhizin also has several bioactivities $(8,9)$. Some of these include chemotherapeutic activity in chronic hepatitis (8) and as an antiviral agent against HIV-1, SARS-related coronavirus, respiratory syncytial virus, arboviruses, vaccinia virus and vesicular stomatitis virus (9). Since there are no reports on the effects of glycyrrhizin on prostate cancer, in the current study we examined the effect of glycyrrhizin on two different prostate cancer cell lines LNCaP (androgendependent) and DU-145 (androgen-independent). Antiproliferative responses of glycyrrhizin on these cell lines and its potential to induce apoptosis were evaluated.

\section{Materials and methods}

Chemicals and reagents. Fetal calf serum (FCS), RPMI-1640 and minimum essential medium (MEM) were obtained from American Type Cell Culture (ATCC), Manasas, VA. Glycyrrhizin was purchased from Sigma-Aldrich (St. Louis, 
MO). The structure of glycyrrhizin [3-O-(2-O-B-D-Glucopyranuronosyl- $\alpha$-D-glucopyranuronosyl)-18ß-glycyrrhetinic acid] is shown in Fig. 1. Cell viably assay kit was purchased from Dojindo Molecular Technologies Inc., Gaithersberg, MD. Annexin V-FITC apoptosis detection kit was obtained from MBL International, Woburn, MA and Caspase assay kits were purchased from R\&D Systems, Minneapolis, MN.

Cell lines and cell culture. Prostate cancer cells, DU-145 and LNCaP were obtained from ATCC. DU-145 and LNCaP were cultured in MEM and RPMI-1640 media respectively and both media were supplemented with $10 \%$ FCS and $50 \mu \mathrm{g} / \mathrm{ml}$ gentamycin. For all experiments, $1 \times 10^{5}$ cells $/ \mathrm{ml}$ were seeded and grown for $24 \mathrm{~h}$ before experimental treatments. Cells were maintained at $37^{\circ} \mathrm{C}, 5 \% \mathrm{CO}_{2}$ environment.

Cell viability assay. Cells were treated for different periods of time with different doses of glycyrrhizin (0.1-20 mM). Cell viability was measured using a CCK-8 kit purchased from Dojindo Molecular Technologies Inc. Briefly, cells were cultured in 96-well plates in the presence of $10 \mu 1$ aliquots of glycyrrhizin at various concentrations ranging from 0.1 to $20 \mathrm{mM}$. Following exposure to glycyrrhizin, $10 \mu 1$ of CCK-8 solution was added to each well, and the plates were incubated for $4 \mathrm{~h}$ at $37^{\circ} \mathrm{C}$ and read immediately at $450 \mathrm{~nm}$ using a microplate reader (Bio-Rad, Richmond, CA).

Agarose gel electrophoresis analysis for DNA fragmentation. LNCaP and DU-145 cells were cultured in 6-well tissue culture plates for $24 \mathrm{~h}$ at $37^{\circ} \mathrm{C}$ in $5 \% \mathrm{CO}_{2}$ environment. Cells were then exposed to $10 \mathrm{mM}$ glycyrrhizin. At the end of experimental period, cells were collected and suspended in $200 \mu 1$ of PBS. DNA was isolated using DNA extraction kit (DNeasy blood and tissue kit, Qiagen) as per the manufacturer's recommendations. The purity of DNA was analyzed in a spectrophotometer at $260 / 280 \mathrm{~nm}$ and ratio was confirmed to be between 1.7 and 1.9. DNA samples were then electrophoresed on a $2 \%$ agarose gel and visualized with ethidium bromide staining under UV illumination.

Assessment of apoptosis in LNCaP and DU-145 cells by flow cytometry. Cells were stained with an Annexin V-FITC apoptosis detection kit (MBL) to determine the percentage of apoptotic cells. Propidium iodide staining was used as a control to differentiate cells undergoing necrosis. Cells $\left(6 \times 10^{5}\right)$ were seeded in $25-\mathrm{cm}^{2}$ flasks and allowed to attach for $24 \mathrm{~h}$. After treating with glycyrrhizin for $72 \mathrm{~h}$, detached and attached cells were collected and washed twice with ice-cold PBS. Subsequently, cells were resuspended in $500 \mu 1$ of $1 \mathrm{X}$ binding buffer, $5 \mu 1$ Annexin V-FITC and $5 \mu 1$ of propidium iodide were added and incubated for $5 \mathrm{~min}$ at $37^{\circ} \mathrm{C}$ in the dark. The number of viable, apoptotic and necrotic cells were quantified by flow cytometer (Becton Dickinson, USA) and data analyzed by CellQuest software.

Caspase activity. Caspase- 3 and -8 activities were measured using colorimetric assay kits (R\&D Systems). After addition of glycyrrhizin, cells were washed with ice-cold PBS and caspase- 3 and -8 activities were determined using the kit following the manufacturer's recommendations. Caspase

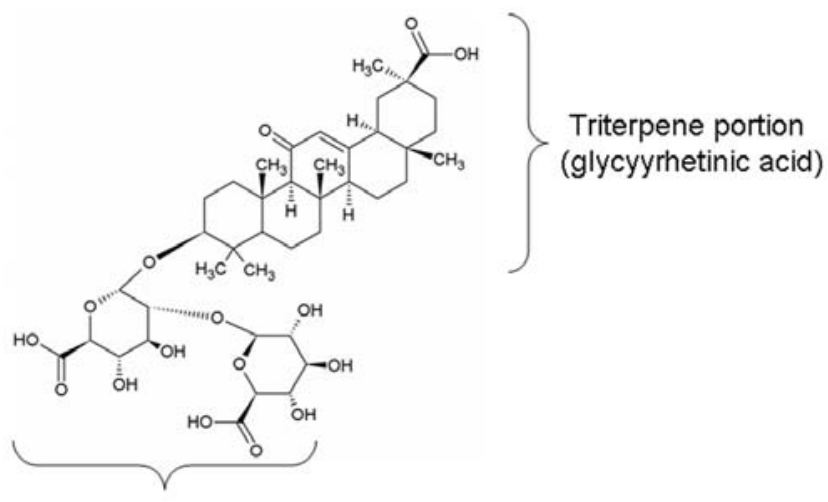

Iduronic acid

Figure 1. Structure of glycyrrhizin. Glycyrrhizin consists of a triterpene portion (glycyyrhetinic acid) and two iduronic acid molecules.

colorimetric substrates DEVD-pNA (caspase-3) or IETDpNA (caspase-8) were added to the cell lysate and assays were performed in a 100- $\mu 1$ volume in 96-well flat-bottomed plates. Chromophore p-nitroanilide is released as a result of cleavage of substrates by caspase activity. The caspase enzymatic activity in the cell lysate is directly proportional to the chromophore formation, which was quantified spectrophotometrically at a wavelength of $405 \mathrm{~nm}$ using a microplate reader. Data were corrected for the background values that had no substrate or no cell lysate treated.

Statistics. Data were compared using the Mann-Whitney rank sum test using the SigmaStat program (Jandel Scientific, San Rafel, CA). P $<0.05$ was considered statistically significant.

\section{Results}

The effect of glycyrrhizin on cell viability. No significant reduction in cell viability was detected when low concentrations of glycyrrhizin (1-2 $\mathrm{mM}$ ) were added to LNCaP and DU-145 cells. However, an inverse relationship was observed between CCK-8 activity (cell viability) and high concentrations of glycyrrhizin $(5-20 \mathrm{mM})$ especially following 48 and $72 \mathrm{~h}$ treatments. With increasing concentration of glycyrrhizin, CCK-8 activity was decreased in LNCaP and DU-145 cells. The ability of glycyrrhizin to decrease CCK-8 activity by $50 \%\left[\mathrm{IC}_{50}\right]$ in $\mathrm{LNCaP}$ and DU-145 cells was achieved at concentrations of 8.5 and $12.5 \mathrm{mM}$ respectively after incubation for $48 \mathrm{~h}$ (Fig. 2). Interestingly, glycyrrhizin at a dose of $8.5 \mathrm{mM}$ significantly $(\mathrm{P}<0.05)$ reduced the viability of LNCaP cells compared to DU-145 cells at 24, 48 and $72 \mathrm{~h}$ time-points. Consistently our results showed that LNCaP cells were more sensitive to glycyrrhizin than DU-145 cells. $\mathrm{IC}_{50}$ values were significantly decreased when the glycyrrhizin concentration was reduced to $5 \mathrm{mM}$ (in LNCaP cells) and to $\sim 10 \mathrm{mM}$ (in DU-145 cells) respectively following incubation of the cells for $72 \mathrm{~h}$.

Glycyrrhizin induces DNA fragmentation. We examined chromosomal DNA fragmentation to confirm apoptosis in cells. LNCaP and DU-145 cells were treated with $10 \mathrm{mM}$ glycyrrhizin for 48 or $72 \mathrm{~h}$. DNA was isolated and analyzed 

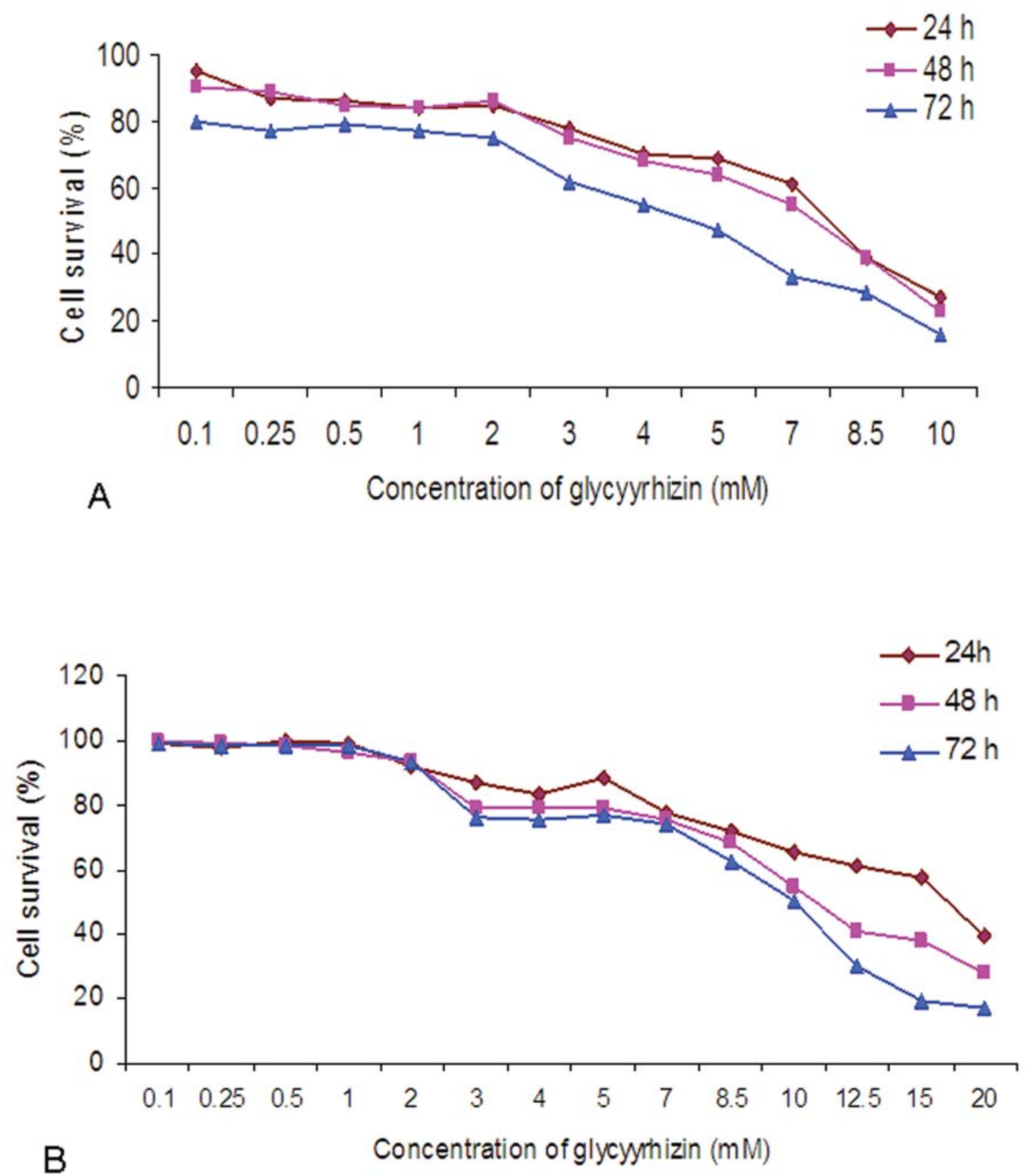

Figure 2. Dose- and time-dependent cytotoxic effects of glycyrrhizin in (A) LNCaP and (B) DU-145 cells. Cells were grown in 96-well plates for $24 \mathrm{~h}$ and were then exposed to glycyrrhizin at serial concentrations for 24,48 and $72 \mathrm{~h}$. Following incubation, viability of cells was determined by MTT assay. Results show that glycyrrhizin significantly decreased the viability of LNCaP and DU-145 cells. Data are representative of one of five similar experiments.

by agarose gel electrophoresis. As shown in Fig. 3, glycyrrhizin treatment induced DNA degradation in LNCaP and DU-145 cells suggesting that the cells treated with glycyrrhizin may be undergoing apoptosis.

Caspase- 3 and -8 activities. Since the above studies suggested that glycyrrhizin may be inducing apoptosis in the cancer cell lines, we wanted to determine whether this involved caspase- 3 or -8 activities. A chromogenic caspase- 3 and -8 substrates was used to directly examine the role of these caspases in glycyrrhizin-treated cells. Results showed that caspase-3 and -8 were not activated in glycrrhizin-treated LNCaP and
DU-145 cell lines $(\mathrm{P}>0.1)$ compared to untreated controls (Fig. 4).

Analysis of Annexin V-FITC/PI staining. Annexin V-FITC assay was used to further confirm glycyrrhizin induced apoptosis in LNCaP and DU-145 cells. Annexin V is a phospholipid-binding protein that has a high affinity for membrane phospholipid phosphatidylserine (PS). During the early stage of apoptosis PS is translocated from the inner leaflet to the outer surface of the plasma membrane (10). PI staining of DNA occurs due to loss of plasma membrane integrity. Hence, staining with Annexin V-FITC was used in 


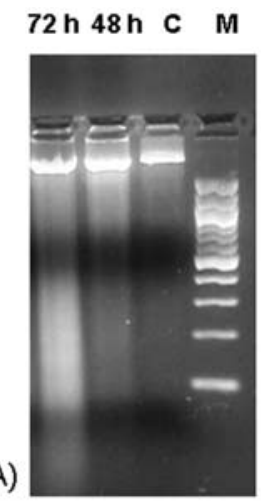

(B)

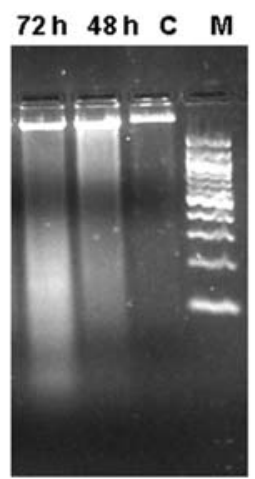

Figure 3. Glycyrrhizin causes DNA fragmentation. LNCaP (A) and DU-145 (B) cells were incubated with $10 \mathrm{mM}$ glycyrrhizin for 48 and $72 \mathrm{~h}$. The genomic DNA was isolated and analyzed on $2 \%$ agarose gel with ethidium bromide staining. M: DNA marker; C: untreated control cells. Results are representative of one of three similar experiments performed.

combination with propidium iodide to detect apoptotic and necrotic cells. Double staining with Annexin V and propidium iodide will indicate that cells are in the late stage of apoptosis or already dead at this stage.

Results from flow cytometric analysis (Fig. 5) also revealed that $10 \mathrm{mM}$ glycyrrhizin treatment for $72 \mathrm{~h}$ increased the percentage of Annexin V-stained cells and induced an early apoptotic change in $>94 \%$ LNCaP cells and $\sim 40 \%$ in DU-145 cells. The total apoptotic DU-145 cell population was increased to $63.62 \%$ after treatment with glycyrrhizin. The Annexin V and PI double positive DU-145 cells were also significantly increased following glycyrrhizin treatment. In contrast, the cells without glycyrrhizin treatment demonstrated normal cell viability with no remarkable cell death.

\section{Discussion}

Natural compounds are widely preferred for treatment of different diseases including cancer as they have minimal side effects. Glycyrrhizin, a natural, biologically active substance isolated from licorice root is shown to have several therapeutic properties including anti-inflammatory (11) anti-viral activity $(12,13)$ and anti-tumorigenic properties $(14,15)$. Glycyrrhizin is a triterpenoid consisting of glycyrrhetinic acid and two iduronic acid residues. Earlier studies showed that glycyrrhizin can induce varying degree of apoptosis in cancer cells depending upon concentrations $(2-12 \mathrm{mM})$ and cell lines used $(6,7,16,17)$. At a concentration of $12 \mathrm{mM}$ glycyrrhizin induced $100 \%$ apoptosis in human stomach cancer KATO III and promyelotic leukemia HL-60 cell lines. Whereas, normal cells from healthy volunteers were found to be resistant to cell growth inhibition and apoptotic induction by glycyrrhizin at least up to the concentration of $12 \mathrm{mM}(6,7)$ suggesting glycyrrhizin is a safe and non-toxic natural product. Results presented in this study support these earlier findings and further show that glycyrrhizin has potential anti-prostate cancer effect.

Cell viability assay in our studies demonstrated that exposure of LNCaP and DU-145 cells to glycyrrhizin significantly decreased the viability of these prostate cancer cells in a time- and dose-dependent manner. Of these two
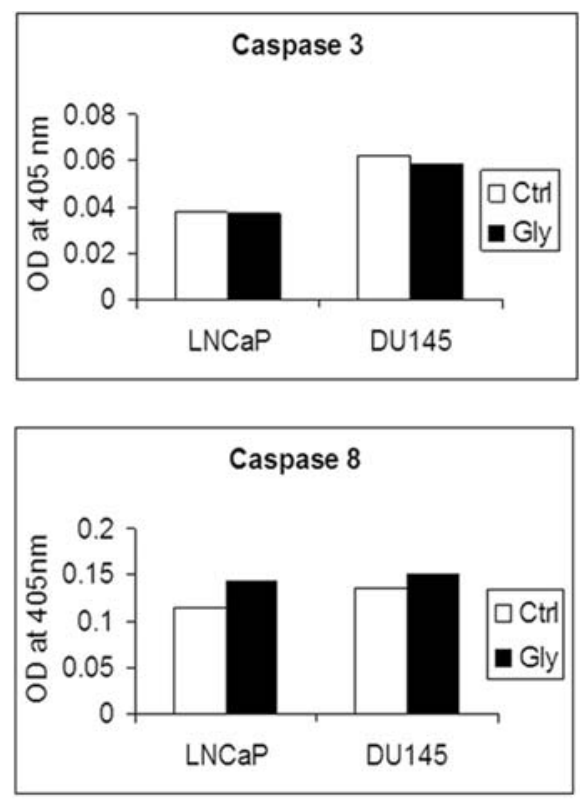

Figure 4. Detection of caspase activities in glycyrrhizin-treated prostate cancer cells. LNCaP and DU-145 cells were treated with glycyrrhizin for 3 days, and $100 \mu \mathrm{g}$ of protein from each sample were analyzed for caspase- 3 and -8 activities by colorimetric assay. These results showed that no significant caspase-3 or -8 activities were found in LNCaP and DU-145 cells. Data are representative of one of four similar experiments.

cell lines, $\mathrm{LNCaP}$ was more susceptible to glycyrrhizin than DU-145. Mechanism of glycyrrhizin-induced cell death in the prostate cancer cell line appears to be apoptosis as evidenced by Annexin V-PI staining, which identifies early and late apoptotic changes in cells. Our studies also show that LNCaP cells, which are androgen-dependent, appeared to be more susceptible to the apoptotic action of glycyrrhizin, than DU-145 cells that are androgen-independent prostate cancer cells. Understanding the molecular events of tumorigenesis is essential for the development of therapeutic treatments of cancer. Transition from androgen-dependent to androgenindependent stage is associated with increasing resistance to induction of apoptosis in prostate cancer progression (18). This is the reason why most chemotherapeutic agents fail with androgen-independent prostate cancer cells. In this study, we tested whether glycyrrhizin has apoptotic effect in LNCaP and DU-145 cells. Glycyrrhizin induced higher apoptotic responses in LNCaP cells, although the effect was lower in DU- 145 cells.

Glycyrrhizin has the potential to decrease serum androgen levels and bind to androgen receptor (19-22). LNCaP cells carry androgen receptors on their surface whereas DU-145 cells do not and yet both cells are susceptible to apoptotic death induced by glycyrrhizin. It is possible that glycyrrhizin might be inducing apoptosis by distinct mechanisms in these two cell lines.

Another possible reason is that the tumor suppressor gene p53 is mutated in DU-145 cells (23). This might explain the reduced cytotoxic effect of glycyrrhizin on DU-145. A study conducted by Curreli et al (16) showed that glycyrrhizin can induce p53-mediated apoptosis in KSHV-infected B lymphocytes suggesting that the status of p53 may be important for the cytotoxic function of glycyrrhizin. 


\section{A. LNCaP}


\section{Annexin V}

\section{B. DU-145}
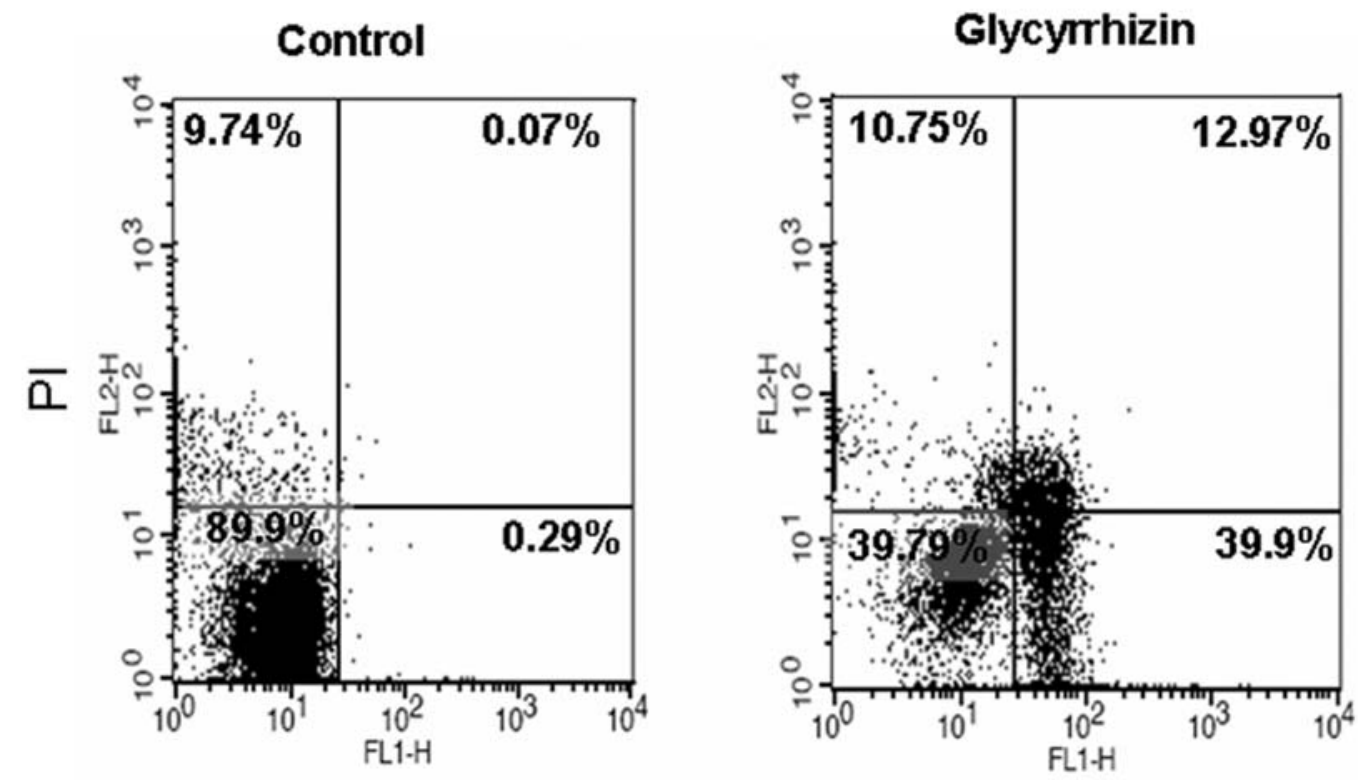

Annexin $\mathrm{V}$

Figure 5. Glycyrrhizin induced cytotoxicity in (A) LNCaP and (B) DU-145 cells. Cells treated with $10 \mathrm{mM}$ of glycyrrhizin for $72 \mathrm{~h}$ and negative control groups were double-stained with Annexin V and PI and analyzed by flow cytometry. Gate setting distinguish between living (bottom left), necrotic (top left), early apoptotic (bottom right), and late apoptotic (top right) cells. Results show that glycyrrhizin induced significant apoptosis in LNCaP and DU-145 cells. Data are representative of one of three similar experiments.

Since the mechanism of cell death following glycyrrhizin appears to be apoptotic, we evaluated whether caspasedependent pathways are activated following treatment with glycyrrhizin. Our results showed that glycyyrhizin did not activate caspase- 3 or -8 in LNCaP and DU-145 cells. This observation support previous studies where glycyrrhizin failed to induce caspase activity in HLE and KATO III cells, yet was able to induce apoptosis in these cells (7). These results thus suggest that glycyrrhizin potentially trigger a caspase- independent apoptotic pathway in its target cells. Studies by Curreli et al showed that four days after treatment with glycyrrhizin, there was translocation of apoptosis-inducing factor (AIF) to the nucleus of KSHV-infected B cells (16). AIF is released by the mitochondria in disparity to cytochrome $\mathrm{c}$ and activates caspase-independent apoptosis pathway. AIF is a mitochondrial intermembrane flavoprotein with oxidoreductase that induces chromatin condensation and DNA fragmentation (24-26). Although we did not study the 
translocation of AIF, we did observe DNA fragmentation in LNCaP and DU-145 cell lines when exposed to glycyrrhizin, thus confirming that apoptosis resulting from exposure to glycyrrhizin in LNCaP and DU-145 cells is possibly via the caspase-independent pathway.

The current study thus provides evidence of an antitumorigenic activity for glycyrrhizin against prostate cancer cells. Androgen-dependent LNCaP cells appeared to be more vulnerable to glycyrrhizin treatment compared to androgenindependent DU-145 cells. Nevertheless, glycyrrhizin treatment induced apoptosis in both cell lines. Glycyrrhizin-induced apoptosis appears to be not mediated by caspase activation. These findings suggest that glycyrrhizin has the potential as a therapeutic agent against prostate cancer. Further studies are needed to evaluate the mechanism of apoptosis induced by glycyrrhizin in prostate cancer cells and its ability to kill prostate cancer cells in vivo.

\section{Acknowledgements}

This study was supported by the Excellence in Academic Medicine (EAM) award of Swedish American Health System.

\section{References}

1. Jemal A, Siegel R, Ward E, Murray T, Xu J and Thun MJ: Cancer statistics, 2007. CA Cancer J Clin 57: 43-66, 2007.

2. Mettlin C: Recent developments in the epidemiology of prostate cancer. Eur J Cancer 33: 340-347, 1997.

3. Denmeade SR and Isaacs JT: Development of prostate cancer treatment: the good news. Prostate 58: 211-224, 2004.

4. Cassileth BR and Deng G: Complementary and alternative therapies for cancer. Oncologist 9: 80-89, 2004.

5. Cragg GM and Newman DJ: Plants as a source of anti-cancer agents. J Ethnopharmacol 100: 72-79, 2005.

6. Hibasami H, Iwase H, Yoshioka K and Takahashi H: Glycyrrhizin induces apoptosis in human stomach cancer KATO III and human promyelotic leukemia HL-60 cells. Int J Mol Med 16: 233-236, 2005.

7. Hibasami H, Iwase H, Yoshioka K and Takahashi H: Glycyrrhetic acid (a metabolic substance and aglycon of glycyrrhizin) induces apoptosis in human hepatoma, promyelotic leukemia and stomach cancer cells. Int J Mol Med 17: 215-219, 2006.

8. Arase Y, Ikeda K, Murashima N, Chayama K, Tsubota A, Koida I, Suzuki Y, Saitoh S, Kobayashi M and Kumada H: The long term efficacy of glycyrrhizin in chronic hepatitis $C$ patients. Cancer 79: 1494-1500, 1997.

9. Fiore C, Eisenhut M, Krausse R, Ragazzi E, Pellati D, Armanini D and Bielenberg J: Antiviral effects of Glycyrrhiza species. Phytother Res 22: 141-148, 2008.

10. Martin SJ, Reutelingsperger CP, McGahon AJ, Rader JA, van Schie RC, LaFace DM and Green DR: Early redistribution of plasma membrane phosphatidylserine is a general feature of apoptosis regardless of the initiating stimulus: inhibition by overexpression of Bcl-2 and Abl. J Exp Med 182: 1545-1556, 1995.
11. Capasso F, Mascolo N, Autore G and Duraccio MR: Glycyrrhetinic acid, leucocytes and prostaglandins. J Pharm Pharmacol 35: 332-335, 1983.

12. Ikeda T, Yokomizo K, Okawa M, Tsuchihashi R, Kinjo J, Nohara $\mathrm{T}$ and Uyeda $\mathrm{M}$ : Anti-herpes virus type 1 activity of oleanane-type triterpenoids. Biol Pharm Bull 28: 1779-1781, 2005.

13. De Clercq E: Potential antivirals and antiviral strategies against SARS coronavirus infections. Expert Rev Anti Infect Ther 4: 291-302, 2006.

14. Lee J, Jung E, Park J, Jung K, Park E, Kim J, Hong S, Park S, Lee $S$ and Park D: Glycyrrhizin induces melanogenesis by elevating a cAMP level in b16 melanoma cells. J Invest Dermatol 124: 405-411, 2005.

15. Rahman S and Sultana S: Glycyrrhizin exhibits potential chemopreventive activity on 12-O-tetradecanoyl phorbol-13-acetateinduced cutaneous oxidative stress and tumor promotion in Swiss albino mice. J Enzyme Inhib Med Chem 22: 363-369, 2007.

16. Curreli F, Friedman-Kien AE and Flore O: Glycyrrhizic acid alters Kaposi sarcoma-associated herpesvirus latency, triggering p53-mediated apoptosis in transformed B lymphocytes. J Clin Invest 115: 642-652, 2005.

17. Luo H, Zhang Z, Wu Q, Huang M, Huang W, Zhang D and Yang F: 18ß-glycyrrhetinic acid-induced apoptosis and relation with intracellular $\mathrm{Ca}^{2+}$ release in human breast carcinoma cells. Chin Ger J Clin Oncol 3: 137-140, 2004.

18. Rothermund CA, Kondrikov D, Lin MF and Vishwanatha JK: Regulation of $\mathrm{Bcl}-2$ during androgen-unresponsive progression of prostate cancer. Prostate Cancer Prostatic Dis 5: 236-245, 2002.

19. Fukui M, Kitagawa Y, Nakamura N and Yoshikawa T: Glycyrrhizin and serum testosterone concentrations in male patients with type 2 diabetes. Diabetes Care 26: 2962, 2003.

20. Tamaya T, Sato S and Okada H: Inhibition by plant herb extracts of steroid bindings in uterus, liver and serum of the rabbit. Acta Obstet Gynecol Scand 65: 839-842, 1986.

21. Sakamoto K and Wakabayashi K: Inhibitory effect of glycyrrhetinic acid on testosterone production in rat gonads. Endocrinol Jpn 35: 333-342, 1988.

22. Armanini D, Bonanni G and Palermo M: Reduction of serum testosterone in men by licorice. N Engl J Med 341: 1158, 1999.

23. Carroll AG, Voeller HJ, Sugars L and Gelmann EP: p53 oncogene mutations in three human prostate cancer cell lines. Prostate 23: 123-134, 1993.

24. Cande C, Cecconi F, Dessen P and Kroemer G: Apoptosisinducing factor (AIF): key to the conserved caspase-independent pathways of cell death? J Cell Sci 115: 4727-4734, 2002

25. Daugas E, Nochy D, Ravagnan L, Loeffler M, Susin SA, Zamzami N and Kroemer G: Apoptosis-inducing factor (AIF): a ubiquitous mitochondrial oxidoreductase involved in apoptosis. FEBS Lett 476: 118-123, 2000.

26. Susin SA, Lorenzo HK, Zamzami N, Marzo I, Snow BE, Brothers GM, Mangion J, Jacotot E, Costantini P, Loeffler M, Larochette N, Goodlett DR, Aebersold R, Siderovski DP, Penninger JM and Kroemer G: Molecular characterization of mitochondrial apoptosis-inducing factor. Nature 397: 441-446, 1999. 